\title{
Remembering With and Without Memory: A Theory of Memory and Aspects of Mind That Enable Its Experience
}

\author{
Stan B. Klein \\ University of California, Santa Barbara
}

\begin{abstract}
This article builds on ideas presented in Klein (2015c) concerning the importance of a more nuanced, conceptually rigorous approach to the scientific understanding and use of the construct Memory. I first summarize my model, taking care to situate discussion within the terminological practices of contemporary philosophy of mind. I then elucidate the implications of the model for a particular operation of mind - the manner in which content presented to consciousness realizes its particular phenomenological character (i.e., mode of presentation). Finally, I discuss how the model offers a reconceptualization of the technical language used by psychologists and neuroscientists to formulate and test ideas about memory.
\end{abstract}

Keywords: memory, remembering, subjective temporality, philosophy of mind, consciousness

\begin{abstract}
Among the great primordial concepts of psychology, few are so badly abused and poorly understood today as is "memory." It is the word "memory" which is in this deplorable condition, not so much our knowledge of the realities to which the term has been applied, though to be sure there are many subtleties in these phenomena which still elude us and will continue to do so until the language in which we think about them is rehabilitated. In our technical and quasi-technical usage of "memory" and such related expressions as "remembering," "memories," "memory trace," "recall," "retention," "learning," and "information storage," a number of fundamental distinctions and not-sofundamental metaphors have become jumbled together in a monstrous snarl of ambiguity and confusion. (Rozeboom, 1965, p. 329; emphasis original)
\end{abstract}

The "ambiguity and confusion" that compromise our understanding of the construct Memory is a specific instance of a more general concern about the underdevelopment of theory in psychological science (e.g., Klein, 2014c). A frequently invoked explanation is that psychology is a young science and thus prone to suffer the unavoidable consequences of youthful folly. This mea culpa is featured in the introductory chapter of many psychology textbooks.

This article was published Online First April 12, 2018.

I thank Dan Robinson, Mike Miller, and Kirk Michaelian for their thoughtful comments.

Correspondence concerning this article should be addressed to Stan B. Klein, Department of Psychological and Brain Sciences, University of California, Santa Barbara, CA 93106. E-mail: klein@psych.ucsb.edu
However, as the following quotes suggest, a "growing-pains" account is not particularly compelling.

\begin{abstract}
The confusion and barrenness of psychology is not to be explained by its being a "young science"; its state is not comparable with that of physics, for instance, in its beginnings ... For in psychology, there are experimental methods and conceptual confusion. The existence of the experimental method makes us think that we have the means of getting rid of the problems which trouble us; but problem and method pass one another by (Wittgenstein, 1953/2009, “A Fragment XIV,” p. 371).

Psychological metatheory has remained seriously underdeveloped . . . a psychologist is likely to appeal his decisions about research strategies directly to general methodological principles to an extent to which a physicist or chemist does not . . . a consequence of the unsettled state of psychological metatheory is thus that schools of psychology are distinguished as much by the kinds of experiments that their adherents typically perform as by the theories they espouse. (Fodor, 1968, pp. xiv-xv)
\end{abstract}

Additional examples of a similar nature can be cited. But I think enough has been said to show that we need to search for causes far more nuanced than the benevolent condescension of youthful indiscretion to explain the "confusion and ambiguity" afflicting theory in psychological science. In the next section I discuss a few well-known offenders. For more comprehensive accounts, see Danziger (1997) and Klein (2014c, 2015c, 2016b). 


\section{Identifying the Problems}

Psychologists studying mental constructs often fail to separate its sense (the manner in which one conceives its denotation) from its reference (the object the term means or indicates; e.g., Frege, 1948). This conflation is exemplified by operationalism - an approach to theory building whose foundations trace to the logical positivist movement of the early-to-mid20th century. The essential idea is that the meaning of a construct (i.e., an explanatory variable that is not directly observable) is fully realized by the observable outcomes of the methods used in its measurement. Because the outcomes of measurement are considered both necessary and sufficient for understanding the construct under scrutiny, construct and measurement are treated as coterminous.

Consider the construct Memory. Because memory is "hidden inside the person," investigators rely on the outcomes of memory testswhich are assumed to be observable expressions of an unobservable entity-to detect and assess memory's properties and functions. The construct acquires its meaning (sense) from the operations (reference) used to elicit its behavior. Memory is what memory tests measure.

Although operationalism - in virtue of linking an abstract construct with observable outcomes-initially appeared to confer scientific respectability on theory construction, it now almost universally is seen as irreconcilable with scientific theory and practice (e.g., Bickhard, 2001; Green, 1992; Horst, 2007). Among the reasons is its inherent circularity. The mantra that "memory is what memory tests measure" begs the question by assuming what it is trying to prove (i.e., the claim that behavior elicited by Test $\mathrm{X}$ is a manifestation of memory rests on the presumption that performance on Test $\mathrm{X}$ is underwritten by memory).

In addition, although an act of measurement can establish a specific reference for a construct, it cannot establish its sense (e.g., Horst, 2007; Klee, 1997). By failing to respect the conceptual distinction between sense and reference, the construct is fallaciously viewed as coextensive with the operations used in its measurement.

Despite these concerns (there are others; e.g., Bickhard, 2001), operationalism continues to have considerable influence on method and theory in psychological science (e.g., Green, 1992;
Klee, 1997). Indeed, psychology is considered unique among the sciences in the extent to which methodological sophistication has preceded and outpaced substantive treatment of issues investigated by those methods (e.g., Koch \& Leary, 1992).

The scientific credibility of the construct Memory is also compromised by an unintentional by-product of historical circumstance. Unlike many of the constructs used in the physical sciences (e.g., electron, covalent bond, inertial mass, time dilation, dark matter), mental construct terms (e.g., memory, self, mind, intelligence, imagination, belief, attitudes) were often part of the vernacular long before anyone thought to use them to identify objects of empirical interest. In consequence, theories of memory interweave folk-psychological presuppositions about familiar objects with theoretically sanctioned propositions (e.g., Klein, 2016b). And because scientific presuppositions are seldom subject to critical analysis (e.g., Rescher, 1984), they are largely immune to refutation. In this way, a host of unexamined presumptions have been woven tightly into the fabric of contemporary memory theory (for a discussion, see Klein, 2013a, 2015c).

Although such issues may be of little concern to the lay person, it is essential that academics provide carefully reasoned arguments in support of their premises and the conclusions they sanction. The only justifiable way to employ a construct as an object of scientific inquiry is to do so critically. A conceptually nuanced examination of the linguistic conventions and probative criteria we use to think about memory and its cognates (e.g., remembering, retention) is the surest path to a genuine understanding of what memory is and what is involved in its acquisition, retention, and presentation.

\section{Methodological Sophistication, Conceptual Underdevelopment}

Psychology is awash in data. What is often missing are well-specified theories linking physical observables to abstract constructs (e.g., Danziger, 1997; Klein, 2014c; Margenau, 1950; Torgerson, 1958). To redress this imbalance, practitioners need to pay greater attention to the conceptual clarity of their constructs prior to pushing them into investigative service. To do otherwise is to put the cart before the horse- 
placing uncertain limits on the extent to which we can trust the conclusions we draw from our empirical efforts to reflect nature as it exists independent of those efforts. ${ }^{1}$

These concerns clearly apply to the scientific treatment of "memory." As Tulving (2007) lamented, the construct too often is inseparable from the specific tasks used in its investigation. Unless armed in advance with a conceptually coherent, though temporally provisional (see Footnote 1), sense of what memory consists in, we have no logically sanctioned way to assess whether the data we collect are commensurate with, antithetical to, or independent of the construct being investigated (e.g., Klein, 2014c).

\section{A Diagnosis of Contemporary Memory Research and a Proposal for Its Rehabilitation}

In Klein (2015c), I offered a detailed analysis of the current sense of the construct Memory. In this section and the next, I present a summary of my conclusions. Although a summary, to be fully be appreciated, should not be considered in isolation from the arguments that served as its formative background, presenting a summation unfettered by the evidence martialed in its support accents key points without risk of their being swallowed by that background. In what follows, I adopt the latter approach. Those interested in evidence and argument are referred to Klein (2015c; see also Klein, 2013a, 2014a, 2016a).

\section{The Encoding/Storage/Retrieval Definition in Memory Research: Explaining too Little and Explaining too Much}

But not until we have learned how to think effectively about the formal structure of psychological processes will we be able to pursue the more provocative leads which have been appearing in contemporary research or to attain any genuine understanding of the phenomena to which the concepts of common-sense mentalistic psychology are dedicated. (Rozeboom, 1965, p. 367)

Most theorists define the construct Memory in an overly general way: Memory is a system designed by natural selection to enable the encoding, storage, and retrieval of information encountered in one's past (for reviews, see Klein, 2013b, 2015c $)^{2,3}$. Although this is unquestionably true, it is far too coarse to be a helpful guide to research or theory. If one subscribes to the principle that things do not pop into existence ex nihilo, then, of logical necessity, our mental construct terms-for example, planning, judging, categorizing, remembering, deciding, faith, believing, imagining, desiring, intending, thinking - refer to "something" that must have come from "somewhere" (i.e., they have a causal history $)^{4}$. And because that "somewhere" makes up one's personally experienced past, with the exception of sensation, perception, and genetically programmed acts, the encoding/storage/retrieval definition has the consequence of rendering virtually every mental state a form of memory.

Explaining too little. A well-specified theory of memory certainly needs to include discussion of the preconditions that serve as its causal history. But unless one can demonstrate that (a) characteristics of the preconditions are present in the end product (e.g., the experience of memory) and (b) characteristics not present

\footnotetext{
${ }^{1}$ This is not to imply that a construct's sense and reference must be set in stone prior to using it. Constructs are not static. They grow and flourish, or are cast aside, as new data confirm or disconfirm their hypothesized properties and features (e.g., Kuhn, 1962; Ladyman, 2002; Popper, 1963/ 2004; Trusted, 1987).

${ }^{2}$ Support for the contention that encoding/storage/ retrieval is widely embraced as the necessary and sufficient criterion for a mental event to be afforded memorial status is presented in Klein (2015c). The unquestioning acceptance of this three-pronged definition was put in bold relief at a recent meeting of world leaders on the cellular mechanisms of memory. Attendees gathered to share their views on what memory is - that is, "where and how memory engrams are stored, consolidated, and retrieved" (Poo et al., 2016, p. 1).

${ }^{3}$ Numerous theories of memory have been fashioned specifically to accommodate data collected from the definition's bookends-encoding and retrieval (e.g., Atkinson \& Shiffrin, 1968; Craik \& Lockhart, 1972; Schacter, Chiu, \& Ochsner, 1993). The storage criterion-for which few observable correlates were available prior to the advent of neuroimaging - was initially included in the definition in deference to Aristotle's postulate that "nature abhors a vacuum."

${ }^{4}$ That the content presented to consciousness has a causal history (e.g., Martin \& Deutscher, 1966) is not to imply that it is identical to its state at acquisition. It is well known that numerous changes (e.g., addition, subtraction, recombination) can, and typically do, take place both between and during encoding and retrieval (e.g., Bartlett, 1932; Nadel \& Moscovitch, 1997). The causal connectivity postulate was designed to ensure that the intentional object of consciousness-be it memory, imagination, belief, and so onmaintained some connection to its origin.
} 
in the preconditions are not in the end product (i.e., the preconditions offer an "explanation without remainder;" e.g., Horst, 2007), the argument that the end product is nothing above and beyond its preconditions rests on shaky ground. We have allowed the target of inquiry to be subsumed by its enablers, thereby confusing the "history of the becoming of a thing with an analysis of the thing as it has become" (e.g., Broad, 1923/1937, p. 12).

By conflating the precursors of an outcome (e.g., encoding/storage/retrieval) with the outcome itself (e.g., memory as experienced), we encourage the practice of seeing the end product as little more than its preconditions "in disguise." The danger in so doing is that the construct-intended to provide meaning to the target of inquiry - is articulated absent essential features that are present in the end product, but not in its precursors (for discussion and examples, see Klein, 2015a).

Explaining too much. "Enthusiasts have so strained its interpretation as to make it explain nothing, by reason of the fact that it explains everything" (Whitehead, 1929, p. 6).

A related concern is that the encoding/ storage/retrieval definition fails to allow distinctions to be drawn between memory and the other mental states it enables. Encoding, storage, and retrieval play a part in the genesis of a multitude of mental outcomes. To say of any one that it is "due to" this processual trio is as informative as saying "the event of my birth is a necessary precondition for my ability to walk." Although the causal connection between walking and birth clearly is true, the relation is informationally anemic: Having been born is a necessary precondition for everything I have achieved in life. To avoid explanatory impotency, a criterion must, at a minimum, specify what it excludes as well as what it includes.

If the term Memory, in virtue of its identification with it preconditions, encompasses virtually everything in the class of mental states, then it is not a useful distinction among them. This is not to say that encoding/storage/retrieval play no part in the production of memorial experience. Rather, it is to say that memory is not their inevitable outcome. These same preconditions can (and do) give rise to a variety of nonmemorial mental states-for example, images, thoughts, beliefs, fantasies, plans, stereotypes, attitudes. If we include all mental states and processes whose origins trace to information acquired in one's past under the heading Memory, we stretch the concept to the point at which just about everything we think and do can be taken as some form of memory. Rather than asking, "What is memory?" we might be better served by asking, "What isn't memory?"

In summary, although simple theoriesbecause of their greater explanatory power (i.e., the principle of parsimony) - are often preferred to complex ones (e.g., Horst, 2007), a theory that can explain every outcome does not explain anything. It is more an act of faith than of scientific precision. Such is the case with the encoding/storage/retrieval theory of memory: Although the experiential terminus of this threepronged causal chain can be a memory, it can also be belief, imagination, knowledge, decision, judgment, hope, fear, and so on. If this diversity of phenomena all counts as Memory, the construct becomes a useless distinctiontrivially true and thus uninformative.

\section{Criteria for a Mental State to Qualify as Memory}

In Klein, (2015c), I argued that the conceptual neutering of the construct Memory could be averted by appreciating that memory entails a special mode of presentation. Whereas many mental states derive from past experience, memory is not just from the past. It is also about the past (for discussion, see Klein, 2013b). More, this "aboutness" consists in the feeling that content retrieved into consciousness refers to events and experiences from my past. This feeling is epistemologically and phenomenologically direct. It is not mediated by inference, description, concepts, rational analysis, or interpretation.

As an example, hearing a tune on the radio and knowing it is a Beatles song, does not license the inference that I am having a memory of the tune. In most cases I simply hear a song (and know certain facts about it; e.g., its name, composers, date of composition, and so on). But I do not hear it as a song I heard previously. I may know or infer this to be the case, but typically I do not consider whether my knowledge derives from personal past experience.

By similar reasoning, knowing that my dog's name is Cooper is not an act of memory. It is information presented to consciousness without any hint of connection with my past. I know his 
name and that is that. Of course this content (which, on presentation to consciousness has attained the phenomenological character of knowledge) was acquired in my past. But reexperiencing the act of acquisition plays no role in my phenomenology. And though I may infer that I learned my dog's name in the past, this inference is not concurrent with the content on presentation. $^{5}$

Accordingly, memory is not simply from and about the past. It is from and about $m y$ past. Its mode of presentation entails a direct feeling that content present in consciousness is about the past, and that this aboutness is "personally owned" (e.g., Klein, 2013a, 2015b; Klein \& Nichols, 2012). By personal ownership, I mean that the content retrieved into consciousness (i.e., its intentional object) is presented as "an experience I previously had." The appropriation of the content of experience to one's self is noninferential and prereflective (e.g., Klein \& Nichols, 2012; Klein, 2015b). It is directly given to me as "mine." This possessory custody can be seen as the "mental glue" that binds features of retrieved content (its causal connection to the past and the conscious apprehension of its pastness) into a feeling that the intentional object is a reliving of happenings that transpired previously in my life, a notion to which Tulving referred as autonoesis (e.g., Tulving, 1985, 2005).

In short, memory is not simply the result of presenting previously acquired content to consciousness; this is true of many nonmemorial states. What is critical is the manner in which retrieved content is presented. To qualify as a memory, the content must be accompanied by, or in Locke's terms, "annexed to" (Locke, 1700/ 1975) the feeling that "I originally experienced this content in the past." The word "accompanied" highlights recent findings that feelings of personal ownership are not intrinsic to the intentional object. ${ }^{6}$ They can, and have been, dissociated, e.g., Klein (2013a), (2014a), (2015b); Klein and Nichols (2012). The mental states that result from this interaction are partly determined by subexperiential activity, but these are preconditions of the eventual mental state, not the state itself.

Thus-in contrast to contemporary psychological and neuroscience doctrine (see Klein, 2015c, Sections 3 and 3.1) -mental states involving knowledge, access to one's lexicon, utilization of skills, and so forth, are not acts of memory. Memory is a term that is (or should be) reserved for content whose mode of presentation consists in a direct feeling that one is reliving the circumstances from which that content was acquired. Although the pastness of a mental state may be identified by conceptual or inferential analysis of retrieved content (e.g., "I attended a Jimi Hendrix concert when I was in high school. Since I attended high school in the 1960s, I know the concert was in the past"), such analyses do not justify the ascription of the term Memory. ("Despite this knowledge, I no longer am able to re-live the experience.")

Memory is an experience. To experience a memory is to have an immediate, nonanalytic feeling that my current mental state is coterminous with a state of affairs I experienced in the past. This is accomplished by several individually necessary and (possibly) jointly sufficient criteria: (a) There is a causal connection between content presented to consciousness and the past, (b) content retrieved into consciousness is taken as its intentional object, (c) there is a feeling of pastness accompanying the intentional object, (d) this feeling is noninferential and prereflective, and (e) the past to which the intentional object is annexed is directly felt as "mine" (i.e., personally owned, or, in James', 1890, more colorful terms, accompanied by feelings of warmth and intimacy).

\section{So What, If Anything, Among the Offerings of Contemporary Memory Research, Qualifies as Memory?}

Based on the writings of contemporary scholars, the construct Memory encompasses a diverse collection of exemplars and types. Tulving (2007), only partly tongue-in-cheek (personal communication; 9/20/2017), has counted 256 variants, most of which are framed in terms of the specific tasks used in

\footnotetext{
${ }^{5}$ I am well aware that the above examples fulfill the criteria for the knowledge subtype of the semantic memory system. However, as argued in Klein (2015c), there are no conceptual arguments or empirical grounds that sanction ascription of the term "memory" to acts of knowing (or skills), but not to the (many) nonmemorial states (e.g., beliefs, attitudes, goals) similarly rooted in my past.

${ }^{6} \mathrm{X}$ is an intrinsic property of $\mathrm{Y}$ if $\mathrm{Y}^{\text {' }}$ s having the property $\mathrm{X}$ does not consist in $\mathrm{Y}$ also having a relation, $\mathrm{Z}$, to something else.
} 
their investigation (see also Roediger, Marsh, $\&$ Lee, 2002). Among this fractious cohort, one variant-episodic memory-comes closest to satisfying the criteria enumerated in the previous section.

Unfortunately-like its parent categoryepisodic memory admits to an assortment of definitions, verbal manifestations, and neuroanatomical correlates (for review, see Klein, 2013a, 2015c; Michaelian, \& Sutton, 2017). The account corresponding most closely to the ideas expressed herein is presented in Klein (2013a). This version adheres closely to Tulving's post-1984 conception of episodic memory (e.g., Tulving, 1985, 1993, 2005), with a few emendations. The most important, for our purposes, is that the properties accompanying episodic memory (e.g., subjective temporality, personal ownership) are attributed to operations acting on system-neutral content retrieved into consciousness (see next section), rather than to qualities intrinsic to content stored in a system dedicated to episodic memory. ${ }^{7}$

\section{Situating Memory in the Mind and in Nature}

Thus far I have focused on one particular mental phenomenon - that of memory. But the principles educed in Klein (2015c) apply more broadly. In what follows, I outline a general theory of a specific operation of the mind-the translation of learned content into conscious experience. Although much of what I have to say is a straightforward expansion of arguments from the preceding sections, I think it helpful to make these points explicit.

Few memory researchers take issue with the proposition that expressions of learningbehaviorally or as an object of consciousnessqualify as memory (for discussion, see Klein, 2015c). However, this relation is defensible only if one accepts the additional proposition that memory consists in any mental or behavioral occurrence whose genesis traces to an act of learning. As I argued in the previous section, however, while learning is a necessary precondition for memory, memory is not the inescapable consequence of learning (a similar view is voiced by Ribot, 1882).

\section{Memory and the Mind: Learned Content Is State-Agnostic Prior to Its Presentation to Consciousness}

Contemporary treatments of the difference between learning and memory seldom stray far from the rather pedestrian insight that learning addresses change whereas memory is concerned with something that happens after a change. The goal of the present section is to show that a more fine-tuned distinction between learning and memory has important consequences for how we view the workings of the mind. In the section "Remembering With and Without Memory," I discuss the implications of this distinction for terminology used to describe those workings.

Although expressions of learning need not involve consciousness (habits, well-practiced skills, etc.; e.g., Hasher \& Zacks, 1979), in what follows, I restrict discussion to those that do. Learned content, prior to its experiential realization, is state-agnostic. It may be recruited in the service of belief, memory, judgment, knowledge, goals, thought, imagery, actions, skills, and so forth, but it does not exist as such until it becomes an intentional object under a particular mode of presentation (for argument and evidence, see Klein, 2015c, 2016a).

This is not to say there are no neural modules with modality-specific content at the subexperiential level (e.g., Fodor, 1983). It is to say that there are no subexperiential modules dedicated to the storage, maintenance, and utilization of mental traits and faculties. Most of these acquire their psychological character from the manner in which state-agnostic content is conjoined at retrieval with various motives and procedures to secure a particular mode of presentation. Depending on context and circumstance, the same content can be experienced as imagination, memory, attitude, belief, thought, and so forth.

For example, suppose the content I retrieve is a mental image of Jimi Hendrix holding his

\footnotetext{
${ }^{7}$ Kriegel (2015) recently voiced a similar view: "There is a feeling of pastness associated with episodic memory, but it is built into its attitudinal nature; it does not appear to be at the level of content" (p. 410).
} 
Fender Stratocaster. ${ }^{8}$ This content may be experienced as an image (tout court), a desire (e.g., I wish I owned a Fender Stratocaster), knowledge (e.g., his full name is James Maurice Hendrix), fantasy (I am playing second lead guitar in "The Jimi Hendrix Experience"), memory (I am reliving the time I saw Hendrix play at Woolsey Hall in New Haven), and so forth. In short, prior to being associated with a particular mode of presentation, remembered content remains agnostic with regard to the phenomenological character it will assume after being taken as the intentional object of consciousness. ${ }^{9}$

In summary, although learning and memory often are treated as the unavoidable endpoints of an unbroken causal chain, learning is a necessary condition for an act of memory, but not sufficient. There is no memory until content is made available to, and apprehended by, consciousness under a particular mode of presentation. That is, memory is an experience (although there are a number of subexperiential preconditions that enable its experiential realization-e.g., see Table 1, Item 2). In this sense, the commonly held assumption that there are subexperiential systems capable of being designated as memory (or desire, or attitude, etc.) is called into question. ${ }^{10}$

\section{Memory: Natural and Human Kinds}

Natural kinds are objects or groupings that reflect real distinctions in nature. They are characterized by an ontological stability that renders them independent of the categorizations or the descriptions they are given. Human kinds, in contrast, are not independent of their categorization. Their reality maps to the words used to describe them rather than to things in themselves. Unlike natural kinds, human kinds are subject to changes in character as a result of changes in the language used in their classification (for discussions, see Hacking, 1992; Taylor, 1985).

In Klein (2015c) I attempted to make the case that memory is a natural rather than a human kind. One of my arguments - the stability of usage-received only oblique mention. In what follows, I draw out more fully the implications of that aspect of my argument for the naturalkind status of memory.

\section{Experiential Constancy as a Criterion for Natural-Kind Status}

The view of memory as "content conjoined with a non-inferential feeling of the past as my past" has, at least until recently, a long history in Western thought, tracing to Greek antiquity (reviewed in Klein, 2015c). Over the millennia, the experience of reliving events from one's past has been firmly entrenched as part of human subjective reality (which, in contrast to many in the field, I take to be a part of nature: e.g., Klein, 2016b). Memory, so conceived, does not exist only in some particular cultural context at some particular time.

However, although long-held beliefs about a construct do not usually ensure they capture the natural order (the earth, after all, was believed by many to be the center of the universe for thousands of years), in the domain of personal phenomenology, stability can confer ontological warrant. Apprehension of an intentional object of consciousness - rather than that to which the object refers-is an introspectively given state whose mode of presentation is made fully visible in and by the experience itself: Interpretation of that to which the object refers may be inaccurate (e.g., despite our personal phenomenology, the sun does not travel around the earth), but the interpreter cannot be mistaken about how the intentional object appears (e.g., Gertler, 2011; Shoemaker, 1968). The special epistemic character of first person, present tense

\footnotetext{
${ }^{8}$ Although I have chosen a fixed image for my example, nothing turns on this stasis. Whether retrieved content is static or dynamic, the same general principles obtain.

${ }^{9}$ To avoid potential confusion, let me be clear that the individuation of a mental state as, say, a memory, knowledge, fantasy, or belief is a function of a variety of factors, including, but not limited to, scientific consensus on language used in their characterization, and the nature of the intentional object and the type of (largely subexperiential) routines enacted on the intentional object. Personal ownership enables one to experience possessory custody of a mental state: It is not a determining factor in the type of state experienced.

${ }^{10}$ A similar view of mind and memory is found in Russell (1921). For example, "Memory-images and imagination images do not differ in their intrinsic qualities, so far as we can discover. They differ by the fact that the images that constitute memories, unlike those that constitute imagination, are accompanied by a feeling of belief which may be expressed in the words 'this happened'. The mere occurrence of images, without this feeling of belief, constitutes imagination.” (p. 176).
} 
Table 1

Notes on Some Key Terms Used in This Paper

Terms and definitions

In Table 1, I spell out my intended meaning of terms that play a central role in this paper. My reasons for doing so are two-fold. First, many of these are terms from highly specialized areas of philosophy (e.g., mind, phenomenology, science). Because they are unlikely to be familiar to readers not involved in those research domains, explicit specification of my (perhaps idiosyncratic) usage seems warranted.

Second, some of these terms have several (colloquially accepted) uses (e.g., experience, mind, content); accordingly, a precise treatment of their in-text sense establishes a common reference base. Although not everyone will agree with my definitions, there should be little question of the meanings I intend.

1. Consciousness: Consciousness comes in many kinds (e.g., sentience, access consciousness, noetic consciousness, temporal consciousness, phenomenal consciousness; e.g., Klein, 2012). My use of the term consists in the proposition that $\mathrm{X}$ is conscious if and only if there is something it is like for the organism to be in that state (e.g., Nagel, 1974). That is, consciousness enables first-person experience (see Item 4). This usage is what most philosophers have in mind when discussing phenomenal consciousness.

2. Mental state: $\mathrm{X}$ is a mental state only if and only if it there is "something it is like" for the organism to have the mental state. A mental state contains both content (e.g., objects of consciousness) as well as qualitative (i.e., the subjective feel of the content) aspects. It is thus the experiential (see Item 4) outcome of a process (or set of processes) that can have non-experiential aspects. Although these nonexperiential preconditions are necessary for realizing the mental state, they are nonmental in the sense that they are mechanisms that help make experience possible, but are not the experience per se-that is, as it is felt. They conceivably could go on without there being any experience. An analogy may help: A play consists in a great deal of behind-the-scenes activity (e.g., funding, auditions, permits), but, strictly speaking, none of this activity is the play per se. All mental states are experiential in the sense described in Item 4.

Important note: In this paper I restrict usage of the mental state to situations in which the intentional object refers to content retrieved into consciousness. The term is not meant to refer to circumstances in which the intentional object originates from an occurrent act of perception or sensation, though, in actuality, mental state describes equally well both situations. My motivation for selective application is not based on theory or convention. Rather, it is done for expository convenience (the arguments I present in the text pertain only to the former usage).

3. Mind: Mind is the collection of subexperiential processes required for having a mental state, in addition to the mental states they enable.

4. Experience: Experience is the qualitative aspect of the mental states you are having right now. Although experience is what most philosophers have in mind when they talk about consciousness, in my usage, consciousness must be accompanied by an intentional object (see Item 6) to produce subjective experience. Accordingly, all experience is conscious experience. Although some who use the term "experience" have "sensation" in mind (e.g., pain) and perception (e.g., that tree over there), experience, as I use the term, can take as its intentional object (see Item 6) such things as thought, belief, memory and other mental content. In this way, experience can be cognitive as well as sensory.

5. Experience and feeling: Although some philosophers hold that a feeling is an additional mental item accompanying the experienced content of a mental state, for my purposes nothing substantive rides on this distinction. Accordingly, when I use the term "feeling" I refer to the qualitative mode in which a mental state is apprehended. In my sense, all experience is felt-i.e., it is the particular "what it is like-ness" of the mental state you are having right now.

6. Mental content, intentional objects, and mode of presentation: A distinction can (and should) be drawn between the intentional objects of consciousness and the content to which those objects refer or are directed. Content refers to any neurally realized material of interoceptive or exteroceptive origin (after initial registration, this material often undergoes extensive reworking; e.g., Bartlett, 1932). When presented to consciousness, content becomes its intentional object. The intentional object refers to the proposition that all conscious experiences have objects (i.e., content) to which they referthat is, they are about something (e.g., Brentano, 1995; Smith, 1989). Thus, although every conscious experience takes some content as its intentional object, not all content is realized as an intentional object (e.g., it becomes an intentional object if and only if it is presented to consciousness. Otherwise it exists solely in a nonexperiential property of mind).

The way in which content is presented to consciousness is referred to as the content's mode of presentation, which is determined by the content presented to consciousness in addition to the manner in which that content is characterized (i.e., its phenomenological sense). For instance, depending on the mode of presentation, the same content can be taken by consciousness as a memory, belief, knowledge, precept, etc. In the case of memory, mode of presentation (i.e., subjective colouring) derives from two related, but independent, sources: (a) The content taken as the intentional object of consciousness is felt to be a direct, noninferential reexperiencing of the past (subjective past temporality), and (b) the feeling of personal ownership-i.e., the occurrences and experiences reflected by the intentional object happened to me in my past. The claim of independence is secured by findings that individuals can (a) experience past-oriented subjective temporality absent a feeling of personal ownership (e.g., Klein, 2013a, 2016a; Klein \& Nichols, 2012), and (b) experience personal ownership absent a feeling of temporal reference (e.g., Klein, 2014b, 2016a; Klein \& Steindam, 2016). 
Terms and definitions

7. Precondition: I occasionally talk about nonmental preconditions (e.g., the operations of encoding, storage, and retrieval). These preconditions, though necessary for a mental state (see Item 2), are not sufficient for its realization. They are "building blocks" that can, when combined in the proper manner with a particular subjective context (e.g., temporally propertied and personally owned) eventuate in a particular mental state (e.g., a memory).

The building-block metaphor may help unpack my intended meaning. Encoding, storage and retrieval (to use memory as my example) can be viewed as the building blocks that, when conjoined with the proper "instructions" (internal or external context; preexisting neural pathways, etc.) and subjective feelings of pastness, result in a memorial experience. But these building blocks, are no more memory than a collection of building material and a set of blueprints is a house. Under different circumstances (different contexts, different plans, and so on) they can be used to construct any number of mental and non-mental outcomes. They are necessary, not sufficient.

8. Presuppositions in science: Presuppositions are widely held, but largely unexamined, beliefs about a construct. These beliefs often play a substantial role in determining the questions we ask nature, but they are not facts or truths discovered in virtue of critical analyses of the answers we receive. Some presuppositions may facilitate the performance of scientific inquiry, but what is important to note is that they are not formally part of science.

psychological statements is typically referred to as immunity to error through misidentification (IEM).

The psychological topography of our mental constructs ultimately must be fitted to first-person acquaintance with the experiential acts in which they are realized (e.g., Gallagher, \& Zahavi, 2008; Strawson, 2009). A conceptualization of personal experience drawn entirely in analytic way is a discourse about experience, not a rendering of the experience (e.g., Georgalis, 2006; Varela, Thompson, \& Rosch, 1993).

In contrast to the stability of reports concerning the experience of memory, many of our mental traits and faculties-for example, motivation, consciousness, self, personality, depression, attitudes - have been subject to considerable revision and reconsideration over the millennia (e.g., Danziger, 1997; Uttal, 2001). These variations derive primarily from scholarly negotiations embedded within particular cultural contexts. As Danziger observes, "the categories one meets in psychological texts are discursive categories, forms of words, not the things themselves" (1997, p. 186). And when categorizations change as a function of historical context, the suspicion arises that a construct's meaning is being negotiated and renegotiated by groups to whom it matters (e.g., Wittgenstein, 1997) - that is, description is more an act of construction than of discovery.

In short, the act of categorizing mental phenomena can (and typically does) vary as a function of specific discursive practices. Indeed, it is a live question whether persons untutored in the psychological and philosophical dogma of their time would find experiential grounds for distinguishing between mental states such as knowledge, belief, and faith.

An exception to this view of mental traits and faculties as a discursive categories is memory. Historical and phenomenological evidence suggest the temporal and cultural stability of the construct (as used herein) captures a clearly delimited aspect of human nature-one whose experiential description maps to something that exists independently of the language used to describe it. Although stability is no guarantee of natural kind status, in the context of mental phenomena, consistency of usage provides good reason to believe we are closer to cutting nature at an ontological seam than we are for the more labile constructs that populate contemporary mental topographies.

\section{Remembering With and Without Memory}

In 1965 Rozeboom argued for a "wholesale re-examination and tightening up of how we think about psychological phenomena" (p. 330; emphasis in original). To this end, he presented an analysis of the concept "memory" as well as a grammatical examination of its cognates. Based on his analyses, he concluded that

our propensity for thinking in loose metaphors when we should be trying for carefully wrought sentences that say precisely what we want them to say too often fogs our recognition of the very technical details that 
are most seminal for further research and theory. (Rozeboom, 1965; p. 363) ${ }^{11}$

It is not my intent to review Rozeboom's work or to compare his ideas with mine (where points of contact exist, we are in general agreement). Rather, I draw on the ideas outlined in the present article to show that the technical language used to investigate and describe memory phenomena often has considerably less to do with memory than is appreciated by memory research. $^{12}$

In what follows, I focus on the use of the cognate "remember." Among memory scholars, "remember", first and foremost, is a specific expression of the more general process of "retrieval" featured in the 3-pronged definition of memory. "Remember" is treated as an achievement verb (it also can take noun form; Binnick, 1991) used to designate something subject $X$ does to content Y. Specifically, "X remembers Y" (e.g., that Hartford is the capital of Connecticut; that I ate steak for dinner). And, of definitional necessity, the experiential terminus of this doing is having a memory. The idea that "to remember is to retrieve memories" is so deeply engrained in the technical language of memory (cf., Mace, 2010) that it essentially is taken as axiomatic.

But, scientific presuppositions, however firmly rooted in thought, language and practice, are not inviolable laws: They are postulates that color how we think about nature, not how nature itself is constituted. As Rescher (1984) observes, they are "a matter of the particular systematization of knowledge we find it convenient to adopt." (p. 11). The sense and reference of the word "remember" - like all memorywords-requires an explicit, rigorous account. Only in this way can we determine the extent to which research on memory "substantiates, refines, repudiates or is otherwise relevant to" (Rozeboom, 1965, p. 332) our presuppositions.

Considered in the context of arguments I have presented, contemporary treatments of "remember" confuse the act of remembering with the object remembered. This confusion is the predictable consequence of the (often tacit) presupposition that "remember" and "memory" are inseparably yoked as process and product. But, as I have argued, remembering does not imply that retrieved content necessarily will result in memorial experience. Although remembering makes content originating from past experience available, that content remains state-neutral until it assumes a particular mode of presentation. And that mode does not have to be the feeling that I am reexperiencing something that happened to me in my past. It can be experienced as a host of mental states, which though having a causal connection to something that happened to me in my past, is not accompanied by the feeling that I am reliving a past happening. For the outcome of remembering to be memory, the something that happened to me in my past must be descriptive both of the source of the intentional object and its mode of presentation.

For example, I can remember knowledge (e.g., the song on the radio is a Beatle's song; I was born in New York), belief (e.g., Jenny is the school's smartest student; the earth is flat), facts (e.g., $2+2=4$; the sun is approximately 93 million miles from the earth), rules (e.g., a red traffic light means stop; in chess, the bishop moves diagonally), skills (e.g., how to ride a bike; how to play a song on piano). Although each of these intentional objects results from an act of remembering, none, with respect to the ideas presented in this article, is an example of the construct Memory.

I briefly summarize my position. According to the "received view," remembering is a process in which content retrieved from storage culminates in a memorial experience. In contrast, the position I take-which is a logical consequence of my theory of memory and mind-is that, although all memory requires remembering, not all remembering eventuates in memory. To remember means nothing more than that state-agnostic content has been made available as an intentional object consciousness under a particular mode of presentation (be it

\footnotetext{
${ }^{11}$ At the time of its publication, Rozeboom anticipated his attempt to diagnose and unravel some of the conceptual confusion attending the word memory would be met with "indifference, incomprehension, and at times open hostility." (Rozeboom, 1965; p. 329). Unfortunately, his expectation proved prescient: In the 53 years following publication, his article has been cited only 22 times (four in the past 25 years).

${ }^{12}$ I was not aware of Rozeboom's work when I wrote my paper "What memory is" (Klein, 2015c). In light of my discovery, I now view my paper, in part, as a long-overdue attempt to call attention to the important message that Rozeboom predicted, with sad accuracy, would be met with indifference.
} 
memory, belief, attitude, imagination, skill, etc.).

\section{Do Amnesic Patients Know Their Own Experiences?}

Unless a proposal can be shown to have consequences for how we think about and conduct research, it runs the risk of being little more than a squabble over semantics. In this regard, a case can be made that my analysis of the construct Remember is more a philosophical exercise than a scientific proposal.

A comprehensive review of the ways in which my construal of memory can provide a new and fruitful perspective on issues of longstanding debate in memory research would take me well beyond my page limits (see Klein, 2015 c for review). I do, however, want to discuss the implications of my reconceptualization of Remember for one of the more curious phenomena in memory studies - the finding that amnesic patients often demonstrate intact learning despite an avowed absence of memorial experience.

Consider, as our example, the case of patient H. M. ${ }^{13}$ As a result of a surgical resection of his medial temporal lobes, H. M. was rendered profoundly amnesic for events experienced following his procedure (Scoville \& Milner, 1957). Certain aspects of H. M.'s amnesia, however, presented a problem for memory theorists: Despite stating that he lacked memory for any events encountered postsurgically, H. M. nonetheless was able to learn new things (for reviews, see Corkin, 2002; Rosenbaum, Murphy, \& Rich, 2012). The contrast between H. M.'s anterograde amnesia and his spared learning (as evidenced by performance of newly acquired behaviors) presented a dilemma-how could H. M. remember how to execute newly acquired behaviors if he had no memories related to them? These findings were particularly vexing, given the deeply held conviction that "to remember is to have a memory." Clearly, something was seriously amiss.

An answer began to take form by the early 1970s (e.g., Warrington, \& Weiskrantz, 1970). Influenced by the conceptual resources made available by then current philosophical treatment of memory as consisting in multiple, functionally independent systems (for review, see Klein, 2015c), the dissociation between H. M.'s absence of memorial experience and his intact learning ability could be accounted for by the idea that (a) memory exists in a variety of types, (b) the availability of different types of memory can explain performance on different types of tasks (e.g., semantic memory explains how he learns new facts; procedural memory explains how he learns new skills; implicit memory explains how he learns to solve priming tasks; e.g., Corkin, 2002; O'Kane, Kensinger, \& Corkin, 2004; Schmolck, Kensinger, Corkin, \& Squire, 2002), and (c) only the type of memory accompanied by a feeling of reliving (i.e., episodic) was impacted by his surgical procedure.

But how does this explain the apparent unreliability of H. M.'s introspective reports (i.e., his claim that he has no memory of $\mathrm{X}$ despite the ability to perform tasks whose execution requires remembering information about $\mathrm{X}$ )? Isn't uncorrupted access to one's subjectivity guaranteed by IEM?

The explanation was quite simple. H. M.'s faulty reports are not a result of a corruption of introspection, but rather result from terminological ignorance of the "fact" that many forms of memory do not entail a feeling of reexperiencing. H. M. and patients like him need to update their criteria for deciding which experiential states count as a memory.

Contemporary memory theorists have almost universally embraced this explanation of amnesic dissociative behavior (for reviews, see Campbell \& Conway, 1995; Cermak, 1982; Mayes, 1988; but see Toth \& Hunt, 1999). However, I believe a more parsimonious account of is possible. My explanation trades in the construal of remembering as a process in which state-neutral content is made available to consciousness under a particular mode of presentation, only one of which culminates in memorial experience (see previous section). From this vantage point, a patient's behavior and subjective experience march in lockstep: As a consequence of neural insult, content still can be remembered and made

\footnotetext{
${ }^{13} \mathrm{H}$. M simply is one example of the widely recognized phenomenon of amnesic learning in the absence of memory for the experiences from which that learning was acquired. I did not originally feel it necessary to note the generality of the phenomenon; but because a reviewer questioned the inferential warrant of "relying on $N=1$," I now do so to avoid confusion on the part of other readers.
} 
available for task performance, but the content is experienced as something other than memory. Its phenomenological character is determined by context and the results of discursive practices of specialized groups for whom these constructs play a role, for example, as knowledge, fact, belief, intuition, skill. Seen thus, it is the memory scholar's criteria-not the patient's-in need of revision.

\section{Final Thoughts}

\begin{abstract}
All the world over and at all times there have been practical men, absorbed in 'irreducible and stubborn facts'; all the world over and at all times there have been men of philosophic temperament, who have been absorbed in the weaving of general principles. It is this union of passionate interest in the detailed facts with equal devotion to abstract generalisation which forms the novelty of our present society. (Whitehead, 1926, p. 3)
\end{abstract}

The proper way to use technical language is to do so knowingly- that is, to conduct a rigorous and carefully delineated examination of the sense and reference of our constructs prior to pushing them into investigative service. Only in this way can we hope to make progress toward determining whether the data we collect refer to things that exist in nature or to things whose existence is contingent on linguistic practices negotiated by the scientific community.

In this paper, I argued that a sustained conceptual analysis of memory and its cognates is seldom found in the psychological and neuroscientific literatures. Rather, professional understanding of these constructs is underwritten by a jumble of folk-psychological presupposition and scientific thought, whose proportions one can only guess. Although I have no way to tell whether my efforts to fill this conceptual void have positioned us on a path to genuine understanding, one thing is certain: Until we fully embrace the need for a more critical attitude toward our constructs, psychology's claim to being a science will remain an assertion in need of defense rather than one of unquestioned acceptance. $^{14}$

\footnotetext{
${ }^{14}$ In the service of full transparency, this final line is a paraphrase of a quote of which I am particularly fond but whose source I no longer remember.
}

\section{References}

Atkinson, R. C., \& Shiffrin, R. M. (1968). Human memory: A proposed system and its control processes. In K. W. Spence \& J. T. Spence (Eds.), The psychology of learning and motivation (Vol. 2, pp. 89-195). New York, NY: Academic Press. http:// dx.doi.org/10.1016/S0079-7421(08)60422-3

Bartlett, F. C. (1932). Remembering. London, UK: Cambridge University Press.

Binnick, R. I. (1991). Time and the verb: A guide to tense and aspect. New York, NY: Oxford University Press.

Brentano, F. (1995). Descriptive psychology. London, UK: Routledge.

Bickhard, M. (2001). The tragedy of operationalism. Theory \& Psychology, 11, 35-44. http://dx.doi .org/10.1177/0959354301111002

Broad, C. D. (1923/1937). The mind and its place in nature. New York, NY: Harcourt, Brace and Company.

Campbell, R., \& Conway, M. A. (1995). Broken memories: Case studies in memory impairment. Cambridge, MA: Blackwell.

Cermak, L. S. (1982). Human memory and amnesia. Hillsdale, NJ: Erlbaum.

Corkin, S. (2002). What's new with amnesic patient H. M.? Nature Reviews Neuroscience, 3, 153-160. http://dx.doi.org/10.1038/nrn726

Craik, F. I. M., \& Lockhart, R. S. (1972). Levels of processing: A framework for memory research. Journal of Verbal Learning and Verbal Behavior, 11, 671-684.

Danziger, K. (1997). Naming the mind: How psychology found its language. Thousand Oaks, CA: Sage.

Fodor, J. A. (1968). Psychological explanation: An introduction to the philosophy of psychology. New York, NY: Random House.

Fodor, J. A. (1983). The modularity of mind: An essay on faculty psychology. Cambridge, MA: MIT Press.

Frege, G. (1948). Sense and reference. The Philosophical Review, 57, 209-230. http://dx.doi.org/10 $.2307 / 2181485$

Gallagher, S., \& Zahavi, D. (2008). The phenomenological mind. New York, NY: Routledge.

Georgalis, N. (2006). The primacy of the subjective: Foundations for a unified theory of mind and language. Cambridge, MA: MIT Press.

Gertler, B. (2011). Self-knowledge. New York, NY: Routledge.

Green, C. D. (1992). Of immortal mythological beasts: Operationalism in psychology. Theory \& Psychology, 2, 291-320. http://dx.doi.org/10.1177/ 0959354392023003

Hacking, I. (1992). Word-making by kind-making: Child abuse for example. In M. Douglas \& D. Hull (Eds.), How classification works: Nelson Good- 
man among the social sciences (pp. 180-238). Edinburgh, UK: Edinburgh University Press.

Hasher, L., \& Zacks, R. (1979). Automatic and effortful processes in memory. Journal of Experimental Psychology: General, 108, 356-388. http:// dx.doi.org/10.1037/0096-3445.108.3.356

Horst, S. (2007). Beyond reduction: Philosophy of mind and post-reduction philosophy of science. New York, NY: Oxford University Press. http://dx .doi.org/10.1093/acprof:oso/9780195317114.001 .0001

James, W. (1890). Principles of psychology: Vol. 1. New York, NY: Henry Holt. http://dx.doi.org/10 $.1037 / 10538-000$

Klee, R. (1997). Introduction to the philosophy of science: Cutting nature at its seams. New York, NY: Oxford University Press.

Klein, S. B. (2012). The self and its brain. Social Cognition, 30, 474-518. http://dx.doi.org/10.1521/ soco.2012.30.4.474

Klein, S. B. (2013a). Making the case that episodic recollection is attributable to operations occurring at retrieval rather than to content stored in a dedicated subsystem of long-term memory. Frontiers in Behavioral Neuroscience. Advance online publication. http://dx.doi.org/10.3389/fnbeh.2013 .00003

Klein, S. B. (2013b). The temporal orientation of memory: It's time for a change of direction. Journal of Applied Research in Applied Memory \& Cognition, 2, 222-234. http://dx.doi.org/10.1016/j .jarmac.2013.08.001

Klein, S. B. (2014a). Autonoesis and belief in a personal past: An evolutionary theory of episodic memory indices. Review of Philosophy and Psychology, 5, 427-447. http://dx.doi.org/10.1007/ s13164-014-0181-8

Klein, S. B. (2014b). Sameness and the self: Philosophical and psychological considerations. Frontiers in Psychology, 5, Article 29.

Klein, S. B. (2014c). What can recent replication failures tell us about the theoretical commitments of psychology? Theory \& Psychology, 24, 326338. http://dx.doi.org/10.1177/0959354314529616

Klein, S. B. (2015a). A defense of experiential realism: The need to take phenomenological reality on its own terms in the study of the mind. Psychology of Consciousness: Theory, Research, and Practice, 2, 41-56. http://dx.doi.org/10.1037/cns0000036

Klein, S. B. (2015b). The feeling of personal ownership of one's mental states: A conceptual argument and empirical evidence for an essential, but underappreciated, mechanism of mind. Psychology of Consciousness: Theory, Research, and Practice, 2, 355-376. http://dx.doi.org/10.1037/cns0000052

Klein, S. B. (2015c). What memory is. WIREs Cognitive Science, 6, 1-38. http://dx.doi.org/10.1002/ wcs. 1333
Klein, S. B. (2016a). Autonoetic consciousness: Reconsidering the role of episodic memory in futureoriented self-projection. The Quarterly Journal of Experimental Psychology, 69, 381-401. http://dx .doi.org/10.1080/17470218.2015.1007150

Klein, S. B. (2016b). The unplanned obsolescence of psychological science and an argument for its revival. Psychology of Consciousness: Theory, Research, and Practice, 3, 357-379. http://dx.doi .org/10.1037/cns0000079

Klein, S. B., \& Nichols, S. (2012). Memory and the sense of personal identity. Mind, 121, 677-702. http://dx.doi.org/10.1093/mind/fzs080

Klein, S. B., \& Steindam, C. (2016). The role of subjective temporality in future-oriented mental time travel. In K. Michaelian, S. B. Klein, \& K. Szpunar (Eds.), Seeing the future: Theoretical perspectives on future-oriented mental time travel (pp. 135-152). Oxford, UK/New York, NY: Oxford University Press. http://dx.doi.org/10.1093/ acprof:oso/9780190241537.003.0007

Koch, S., \& Leary, D. E. (Eds.). (1992). A century of psychology as science. Washington, DC: American Psychological Association. http://dx.doi.org/ 10.1037/10117-000

Kriegel, U. (2015). Experiencing the present. Analysis, 75, 407-413. http://dx.doi.org/10.1093/analys/ anv039

Kuhn, T. S. (1962). The structure of scientific revolutions. Chicago, IL: University of Chicago Press.

Ladyman, J. (2002). Understanding philosophy of science. New York, NY: Routledge. http://dx.doi .org/10.4324/9780203463680

Locke, J. (1975). An essay concerning human understanding (pp. 1689-1700). Oxford, UK: Clarendon Press.

Mace, J. H. (Eds.). (2010). The act of remembering: Toward an understanding of how we recall the past. Malden, MA: Wiley-Blackwell. http://dx.doi .org/10.1002/9781444328202

Margenau, H. (1950). The nature of physical reality. New York, NY: McGraw-Hill.

Martin, C. B., \& Deutscher, M. (1966). Remembering. Philosophical Review, 75, 161-196. http://dx .doi.org/10.2307/2183082

Mayes, A. R. (1988). Human organic memory disorders. New York, NY: Cambridge University Press. http://dx.doi.org/10.1017/CBO9780511574597

Michaelian, K., \& Sutton, J. (2017). Memory. E. N. Zalta (Ed.), The Stanford encyclopedia of philosophy (Summer 2017 ed.), Retrieved from https:// plato.stanford.edu/archives/sum2017/entries/memory/

Nadel, L., \& Moscovitch, M. (1997). Memory consolidation, retrograde amnesia and the hippocampal complex. Current Opinion in Neurobiology, 7, 217-227. http://dx.doi.org/10.1016/S0959-4388 (97)80010-4 
Nagel, T. (1974). What is it like to be a bat? The Philosophical Review, 83, 435-450. http://dx.doi .org/10.2307/2183914

O’Kane, G., Kensinger, E. A., \& Corkin, S. (2004). Evidence for semantic learning in profound amnesia: An investigation with patient H. M. Hippocampus, 14, 417-425. http://dx.doi.org/10 .1002/hipo. 20005

Poo, M. M., Pignatelli, M., Ryan, T. J., Tonegawa, S., Bonhoeffer, T., Martin, K. C., . . . Stevens, C. (2016). What is memory? The present state of the engram. BMC Biology, 14, 40-57. http://dx.doi .org/10.1186/s12915-016-0261-6

Popper, K. (2004). Conjectures and refutations: The growth of scientific knowledge. London, UK: Routledge. (Original work published 1963)

Rescher, N. (1984). The limits of science. Berkeley, CA: University of California Press.

Ribot, T. (1882). Diseases of the memory: An essay in the positive psychology. New York, NY: D. Appleton. http://dx.doi.org/10.1037/12818-000

Roediger, H. L., Marsh, E. J., \& Lee, S. C. (2002). Kinds of memory. In D. L. Medin \& H. Paschler (Eds.), Steven's handbook of experimental psychology: Vol. 2. Memory and cognitive processes (3rd ed., pp. 1-41). New York, NY: Wiley.

Rosenbaum, R. S., Murphy, K. J., \& Rich, J. B. (2012). The amnesias. WIREs Cognitive Science, 3, 47-63. http://dx.doi.org/10.1002/wcs.155

Rozeboom, W. W. (1965). The concept of memory. The Psychological Record, 15, 329-368. http://dx .doi.org/10.1007/BF03393601

Russell, B. (1921). The analysis of mind. London, UK: George Allen \& Unwin.

Schacter, D. L., Chiu, C. Y. P., \& Ochsner, K. N. (1993). Implicit memory: A selective review. Annual Review of Neuroscience, 16, 159-182. http:// dx.doi.org/10.1146/annurev.ne.16.030193.001111

Schmolck, H., Kensinger, E. A., Corkin, S., \& Squire, L. R. (2002). Semantic knowledge in patient H. M. and other patients with bilateral medial and lateral temporal lobe lesions. Hippocampus, 12, 520-533. http://dx.doi.org/10.1002/hipo .10039

Scoville, W. B., \& Milner, B. (1957). Loss of recent memory after bilateral hippocampal lesions. Journal of Neurology, Neurosurgery \& Psychiatry, 20, 11-21. http://dx.doi.org/10.1136/jnnp.20.1.11

Shoemaker, S. (1968). Self-reference and selfawareness. The Journal of Philosophy, 65, 555567. http://dx.doi.org/10.2307/2024121

Smith, D. W. (1989). The circle of acquaintance: Perception, consciousness, and empathy. Boston, MA: Kluwer Academic. http://dx.doi.org/10.1007/ 978-94-009-0961-8

Strawson, G. (2009). Mental reality (2nd ed.). Cambridge, MA: MIT Press. http://dx.doi.org/10.7551/ mitpress/9780262513104.001.0001
Taylor, C. (1985). Human agency and language. Cambridge, UK: Cambridge University Press. http://dx.doi.org/10.1017/CBO9781139173483

Torgerson, W. S. (1958). Theory and methods of scaling. New York, NY: John Wiley.

Toth, J. P., \& Hunt, R. R. (1999). Not one versus many, but zero versus any: Structure and function in the context of the multiple memory systems debate. In J. K. Foster \& M. Jelicik (Eds.), Memory: Systems, process, or function? (pp. 232-272). Oxford, UK: New York: Oxford University Press. http://dx.doi.org/10.1093/acprof:oso/978019 8524069.003.0009

Trusted, J. (1987). Inquiry and understanding. Atlantic Highlands, NJ: Humanities Press International, Inc. http://dx.doi.org/10.1007/978-1-349-18823-9

Tulving, E. (1985). Memory and consciousness. $\mathrm{Ca}$ nadian Psychology, 26, 1-12. http://dx.doi.org/10 $.1037 / \mathrm{h} 0080017$

Tulving, E. (1993). What is episodic memory? Current Directions in Psychological Science, 2, 6770. http://dx.doi.org/10.1111/1467-8721.ep107 70899

Tulving, E. (2005). Episodic memory and autonoesis: Uniquely human? In H. S. Terrace \& J. Metcalfe (Eds.), The missing link in cognition: Origins of self-reflective consciousness (pp. 3-56). Oxford, UK: Oxford University Press. http://dx.doi.org/10 .1093/acprof:oso/9780195161564.003.0001

Tulving, E. (2007). Are there 256 different kinds of memory? In J. S. Narine (Ed.), The foundations of remembering: Essays in honor of Henry L. Roediger, III (pp. 39-52). New York, NY: Psychology Press.

Uttal, W. R. (2001). The new phrenology. Cambridge, MA: MIT Press.

Varela, F. J., Thompson, E., \& Rosch, E. (1993). The embodied mind: Cognitive science and human experience. Cambridge, MA: The MIT Press.

Warrington, E. K., \& Weiskrantz, L. (1970). Amnesic syndrome: Consolidation or retrieval? Nature, 228, 628-630. http://dx.doi.org/10.1038/228 $628 \mathrm{a} 0$

Whitehead, A. N. (1926). Science and the modern world. Cambridge, UK: New York, NY: Cambridge University Press.

Whitehead, A. N. (1929). The function of reason. Boston, MA: Beacon Press.

Wittgenstein, L. (1997). Philosophical investigations (2nd ed.) (G. E. M. Anscombe, Trans.). Oxford, UK: Blackwell.

Wittgenstein, L. (2009). Philosophical investigations (4th rev. ed.) (G. E. M. Anscombe, P. M. S. Hacker, \& J. Schultze, Trans.). West Sussex, UK: Wiley-Blackwell.

Received November 17, 2017 Accepted November 28, 2017 